\begin{tabular}{|c|l|}
\hline Title & Superplastic behavior of A I-coated Mg alloy sheet \\
\hline Author(s) & Tokunaga, Toko; Matsuura, Kiyotaka; Ohno, Munekazu \\
\hline Citation & $\begin{array}{l}\text { Journal of A Iloys and Compounds, 601, 179-185 } \\
\text { https://doi.org/10.1016/.jallcom.2014.02.099 }\end{array}$ \\
\hline Issue Date & 201407-15 \\
\hline Doc URL & http://hdl.handle.net/2115/57600 \\
\hline Type & article(author version) \\
\hline File Information & JALCOM_TTokunaga.pdf \\
\hline
\end{tabular}

Instructions for use 


\section{Superplastic Behavior of Al-Coated Mg Alloy Sheet}

Toko Tokunaga ${ }^{1}$, Kiyotaka Matsuura ${ }^{2}$, and Munekazu Ohno ${ }^{3}$

1 Research Fellow of Japan Society for the Promotion of Science, PhD student, Graduate School of Engineering, Hokkaido University, Kita 13 Nishi 8, Kita-ku, Sapporo, Hokkaido 060-8628, Japan

Email: ue145460@frontier.hokudai.ac.jp

Tel: +81 117066345

2 Faculty of Engineering, Hokkaido University, Kita 13 Nishi 8, Kita-ku, Sapporo, Hokkaido 060-8628, Japan

Email: matsuura@eng.hokudai.ac.jp

3 Faculty of Engineering, Hokkaido University, Kita 13 Nishi 8, Kita-ku, Sapporo, Hokkaido 060-8628, Japan

Email: mohno@eng.hokudai.ac.jp

An Al-coated Mg alloy sheet is fabricated by hot forging an Al-coated Mg alloy plate produced by hot extrusion of a Mg alloy billet together with an $\mathrm{Al}$ plate. The sheet consists of recrystallized fine grains both in the $\mathrm{Mg}$ alloy substrate and $\mathrm{Al}$ coating layer. A thin intermetallic compound layer of $\mathrm{Al}_{3} \mathrm{Mg}_{2}$ formed at the $\mathrm{Al} / \mathrm{Mg}$ interface in the hot-extruded plate. The subsequent hot forging reduces the thickness of the intermetallic layer but induces cracks in the intermetallic compound. This sheet exhibits a large tensile elongation of $550 \%$ at $573 \mathrm{~K}$ and at a strain rate of $1.0 \times 10^{-3} \mathrm{~s}^{-1}$. Notably, a tensile test of an $\mathrm{Al}$ specimen exhibited only $40 \%$ elongation, while that of a $\mathrm{Mg}$ alloy specimen exhibited $800 \%$ elongation. It is suggested that the large elongation of $\mathrm{Al}$ as the coating layer on the $\mathrm{Mg}$ alloy is attributable to the good bonding of the $\mathrm{Al}$ coating layer and the $\mathrm{Mg}$ alloy substrate. The cracks in the intermetallic layer disappear during the tensile tests at elevated temperatures and no cracks are observed in the elongated specimens, which indicates growth of the intermetallic and reparation of the cracks occurred during the low strain-rate hot deformation of the Al-coated $\mathrm{Mg}$ alloy sheet.

Keywords: Mg alloy, composite material, cladding, superplasticity, mechanical property

\section{Introduction}

Mg alloys have the lowest density among all metal structural materials and they are characterized by a very high specific strength. Also, Mg alloys possess other attractive properties such as excellent electromagnetic shielding ability and good recyclability and machinability [1-3]. Due to these advantages, $\mathrm{Mg}$ alloys have a number of applications including automobile and aerospace 
components as well as mobile phone and computer parts [4]. However, the practical usage of $\mathrm{Mg}$ alloys has been limited due to their extremely poor corrosion resistance originating from their high reactivity.

Similarly to $\mathrm{Mg}$ alloys, $\mathrm{Al}$ also has a very low density but it has a much higher corrosion resistance than Mg alloys [5, 6]. Thus, it has been expected that $\mathrm{Al}$ coating on Mg alloys should be an effective way to improve their corrosion resistance. Recently much effort has been devoted to the development of Al coating techniques including plating [7], anodizing [8, 9], thermal spray [10-13] and laser cladding $[14,15]$. However, in these attempts, several problems still remain unsolved, such as thermal damages of the substrate materials and necessities of surface pretreatments or post-treatments.

The present authors [16] have recently developed a new process for $\mathrm{Al}$ coating on $\mathrm{Mg}$ alloys using a hot extrusion technique It was illustrated that the extruded Al-coated Mg alloy bars and plates exhibit an excellent corrosion resistance, comparable to that of Al. Moreover, it has been demonstrated that the hot extrusion leads to a recrystallized fine grain structure in the Mg alloy substrate. However, Mg alloys are often used as sheet materials in practical applications. Thus, in this study, the Al-coated Mg alloy plate is plastically deformed into a sheet by hot forging. After that the Al-coated $\mathrm{Mg}$ alloy sheet is tensile-tested at elevated temperatures in order to evaluate its behavior under loading conditions. Finally, the deformation mechanisms of both the Mg alloy substrate and $\mathrm{Al}$ coating layer are discussed within the paper.

\section{Experimental procedures}

Al-coated Mg alloy sheets were fabricated by hot forging of Al-coated Mg alloy plates produced by hot extrusion of a $\mathrm{Mg}$ alloy billet together with an $\mathrm{Al}$ plate. The hot extrusion process is described in detail in a previous paper of the present authors [16]. A commercial extruded bar of AZ80 Mg alloy (Mg-8.2mass\%Al-0.56mass\%Zn-0.44mass\%Mn) was used for the substrate material, while a commercial $\mathrm{Al}$ ingot of 99.99 mass\% purity was used for the coating material. An Al plate, prepared from the ingot, was positioned between the extrusion die and the Mg alloy billet prepared from the alloy bar. The materials were hot-extruded together from the container at an extrusion temperature of $553 \mathrm{~K}$ and at an extrusion speed of $2 \mathrm{~mm} \mathrm{~min}^{-1}$. The illustration of the extrusion setup can be found in our previous paper [16].

The extruded plate, having a width of $20 \mathrm{~mm}$ and a thickness of $10 \mathrm{~mm}$, was sectioned perpendicular to the extrusion direction at positions of every $7 \mathrm{~mm}$ from the tip of the extruded plate, in order to produce small samples for hot forging. The thickness of small samples was reduced from 10 to $1.5 \mathrm{~mm}$ by hot forging in order to produce sheet samples. Figure 1 shows the schematic drawing of the hot forging equipment. The die surfaces were sprayed with BN powder for lubrication, before positioned between the hot dies and then forged. The details of hot forging 
conditions are described in Table 1. A dummy sample, having a hole with a thermocouple, was set between the hot dies. The sample was initially utilized to monitor the heating curve, as a means of determining how long the real sample should be held there to reach the forging temperature.

The forged sheets were wire-cut using an electric discharge machine to produce tensile specimens of $5.0 \mathrm{~mm}$ in gage length, $1.2 \mathrm{~mm}$ in width and $1.5 \mathrm{~mm}$ in thickness. The longitudinal direction of the tensile specimens is perpendicular to the extrusion direction. The tensile test was performed at two different initial strain rates of $1.0 \times 10^{-2}$ and $1.0 \times 10^{-3} \mathrm{~s}^{-1}$ and at three different temperatures of room temperature (RT), 473 and $573 \mathrm{~K}$. All the conditions for tensile tests are summarized in Table 2. The specimens were longitudinally sectioned and polished to investigate the microstructures of the $\mathrm{Mg}$ alloy substrate and the interface between the Mg alloy substrate and the Al coating layer, before and after the tensile test. To measure the grain size and to investigate the crystallographic orientations of the grains, electron backscattering diffraction (EBSD) analysis was conducted.

\section{Results}

Cross sections of the extruded plate and forged sheet are shown in Fig. 2. The plate was forged in the vertical direction. In the extruded plate, the $\mathrm{Al}$ coating layer was perfectly-bonded to the $\mathrm{Mg}$ alloy surfaces. As illustrated in Fig. 2 (b), the coating layer was not damaged by hot forging, with neither breaking nor debonding occurring. Thus a hot-extruded Al-coated Mg alloy plate can be successfully hot-forged into a sheet.

The grain structure of the forged sheet was observed and the results are shown in Fig. 3. The microstructures and the crystallographic orientations of the $\mathrm{Al}$ coating layer and $\mathrm{Mg}$ alloy substrate in the forged sheet are shown in Figs. 3 (a) and (b), respectively. The black and white boundary lines represent high (more than $15^{\circ}$ ) and low $\left(2^{\circ}\right.$ to $\left.15^{\circ}\right)$ angle grain boundaries. The average grain sizes of the $\mathrm{Al}$ and $\mathrm{Mg}$ alloy are approximately $2.6 \mu \mathrm{m}$ and $2.0 \mu \mathrm{m}$, respectively. The grain sizes are smaller than those before the hot forging process. The grain size changes are summarized in Table 3. Furthermore, it is evident that both figures consisted mostly of high angled grain boundaries. The grain shape is equiaxed in both the $\mathrm{Al}$ coating layer and the $\mathrm{Mg}$ alloy substrate even though thickness of the sheet was reduced by $85 \%$ in the vertical direction. Therefore, it is clear that both $\mathrm{Al}$ and $\mathrm{Mg}$ alloy were recrystallized during or after the hot forging.

It is known that Mg alloy has a fine grain structure, which exhibits superplastic characteristics [17]. However, it is not certain whether the Al-coated Mg alloy sheet should illustrate such characteristics. Therefore, it is worth conducting tensile tests in order to investigate the superplastic behavior of the obtained sheet.

Figure 4 (a) shows overviews of the specimens before and after the tensile test. The sample exhibited a maximum elongation of $550 \%$ at $573 \mathrm{~K}$ at $1.0 \times 10^{-3} \mathrm{~s}^{-1}$. As can be seen in the figure, there are two necked regions in the sheet after the deformation. The effect of this multiple necking 
on the sheet elongation behavior will be discussed in the following section. Figures 4 (b) and (c) show the nominal stress-strain curves of the tensile tests at different temperatures with strain rates of $1.0 \times 10^{-2} \mathrm{~s}^{-1}$ and $1.0 \times 10^{-3} \mathrm{~s}^{-1}$, respectively. At room temperature the stress immediately drops after reaching a peak. On the other hand, at elevated temperatures, the stress gradually decreases as the strain increases after the peak. The flow stress decreases as the tensile-test temperature increases, but increases as the strain rate increases.

The superplastic model is typically described as [18]:

$$
\sigma=k \varepsilon^{m}
$$

where $\sigma$ is the flow stress, $k$ a material constant and $s$ the steady state strain rate. The strain rate sensitivity exponent, $m$, defined as the slope of a double logarithmic plot of flow stress versus strain rate can be expressed by [18]:

$$
m=\frac{\theta(\ln \sigma 3}{\partial(\ln b)}
$$

A high $m$-value indicates the occurrence of a large elongation [18]. The double logarithmic plots of the flow stress versus strain rate are shown in Fig. 5 for two different tensile test temperatures. These flow stresses are the values at a strain rate of 0.1. The $m$-values of the present Al-coated Mg alloy sheet were approximately 0.2 at $473 \mathrm{~K}$ and 0.4 at $573 \mathrm{~K}$. Generally the superplasticity is characterized by a large deformation accompanied by elongation of more than $500 \%$ and a strain rate sensitivity of more than $0.3[19,20]$. Therefore, the large deformation of the present sheet observed at $573 \mathrm{~K}$ and at $1.0 \times 10^{-3} \mathrm{~s}^{-1}$ can be regarded as the superplastic deformation.

The cross section of the sheet after the tensile test was observed. Figure 6 shows photographs of the cross section of the specimen which showed $550 \%$ of elongation at $573 \mathrm{~K}$ at $1.0 \times 10^{-3} \mathrm{~s}^{-1}$. These photographs clearly illustrate the presence of the $\mathrm{Al}$ coating continuously covering the $\mathrm{Mg}$ alloy substrate without breaking, despite the large elongation. Furthermore, no debonding was observed at the $\mathrm{Al} / \mathrm{Mg}$ interface. Additionally, Fig. 7 depicts the thickness change of the $\mathrm{Al}$ coating layer with respect to the distance from fracture surface. In the aforementioned figure, the average thicknesses of the $\mathrm{Al}$ coating layer of the samples after the extrusion [16] and hot forging are also shown. As is evident, the $\mathrm{Al}$ coating layer still has uniform thickness after $550 \%$ of elongation. Therefore, the $\mathrm{Al}$ coating was also elongated homogeneously together with the Mg alloy substrate. It is important to point out that not only the $\mathrm{Mg}$ alloy substrate but also the Al coating layer was elongated superplastically. As is known pure Al does not exhibit superplastic behavior under the conditions used in this study regarding temperature, strain rate and grain size [21]. Thus, the deformation mechanisms of both $\mathrm{Mg}$ alloy and $\mathrm{Al}$ are discussed in the following section.

\section{Discussion}

\subsection{Deformation mechanism of Mg alloy}


In order to clarify the deformation mechanism of the sheet, the fracture surface was carefully investigated. Figure 8 shows the scanning electron microscope (SEM) images of the fracture surface of the tensile specimen after elongation of $550 \%$. Figures 8 (a), (b) and (c) exhibit the low magnified image of the fracture surface, high magnified image of the Mg alloy part and the higher magnified image of the region indicated by a square in (b), respectively. As can be seen in Fig. 8 (a), large holes and small holes exist in the Mg alloy part. It is known that the cavity nucleation occurs during the superplastic deformation and the fracture follows the connections of the cavities [22-27]. Therefore, it can be deduced that the large holes formed in the cavity interlinkage stage and small holes formed in the final fracture stage. Furthermore, in Fig. 8, the surfaces of individual grains are clearly visible. These grains observed in the fracture surface are typical for the superplastic material exhibiting the grain boundary sliding (GBS) [26]. Hence, it is considered that the deformation mechanism of $\mathrm{Mg}$ alloy during the large elongation was GBS. Figures 8 (b) and (c) display two types of grains, which have smooth and rough surfaces. These grains are indicated as Grain $\mathrm{S}$ and Grain R. It is reported that this rough surface forms in the final stage of the deformation [27]. Thus, it can be concluded that grains that which have rough surfaces (Grain R) separated from other grains just before the occurrence of the fracture, while the grains having smooth surfaces (Grain S) are believed to have separated due to formation of the cavities.

Additionally, filaments were observed on the grains in the fracture surface as indicated with arrows in Fig. 8 (c). Formation of the filaments is known as one of the micro-superplasticity phenomena [28]. This phenomenon was observed in a number of superplastically deformed materials [28-41]. The micro-superplasticity was suggested to correlate with several possible mechanisms: (1) viscous flow due to the existence of liquid-like or semi-liquid phase [29-37]; (2) single crystalline plasticity [38, 39]; (3) severe elongation of cavities under the tensile stress [40]; (4) diffusion creep and the filament growth during the superplastic deformation [41]. However, the testing temperature, $573 \mathrm{~K}$, for the present alloy was only about $0.62 T_{m}$ of pure $\mathrm{Mg}$, much lower than the eutectic temperature of a Mg-Al binary alloy system, $710 \mathrm{~K}$ [39]. Thus, there is little probability of the viscous flow resulted from incipient melting in the present alloy. Moreover, the present fracture surface did not show the O-shaped cavities among the filaments, which is characteristic of the cavity elongation mechanism (3). Therefore, single crystalline plasticity mechanism (2) or diffusion creep and the filament growth mechanism (4) are the most probable mechanisms to develop the filaments in the present alloy. It has been deduced that the rough surface of the Grain R formed during dislocation creep [27]. Therefore, it is feasible to suggest that the filament gradually formed when the fracture occurred due to the diffusion creep as reported in [41].

\subsection{Deformation mechanism of Al}

To check the tensile behaviors of pure $\mathrm{Al}$ and AZ80 Mg alloy, Al sheets and Mg alloy sheets were 
produced by the hot extrusion of $\mathrm{Al}$ and $\mathrm{Mg}$ alloy billets, respectively. The sheets were hot-forged under the same conditions as used for the production of the Al-coated $\mathrm{Mg}$ alloy sheets, and then the $\mathrm{Al}$ and $\mathrm{Mg}$ alloy sheets were tensile-tested under the same conditions: $573 \mathrm{~K}, 1.0 \times 10^{-3} \mathrm{~s}^{-1}$.

The tensile test results are shown in Fig. 9. The significant difference of ductility between pure Al and Mg alloy can be observed in Fig. 9 (a). The multiple necking, which can be observed in the clad sheet in Fig. 4 (a), was not observed in both the specimens in Fig. 9 (a). Furthermore, from Figs. 9 (b) and (c), it can be found that the $\mathrm{Al}$ exhibits only $40 \%$ elongation while Mg alloy shows $800 \%$ elongation.

This result contradicts evidence of the same $\mathrm{Al}$ can be elongated to $550 \%$ when it is used as the coating material on the Mg alloy surface. It is known that the brittle/ductile multilayered composites have been acknowledged to have a remarkable enhancement of ductility. Several studies have been conducted in order to elucidate the mechanisms of ductility enhancement of the brittle material in the composite materials [42-44]. The major reason of the remarkable enhancement of ductility is due to load transfer from the brittle layer to ductile layer in the laminated composites owing to the interaction between the layers [45]. Generally, when necking occurs at a position in a tensile specimen, local elongation is accelerated in that region, resulting in the occurrence of fracture. However, as explained above, the load transfer occurs in the composite material. In the case of the present study, the load transfer can be explained as follows: when the Al coating layer is bonded to the $\mathrm{Mg}$ alloy substrate, the necking and the subsequent local elongation of the $\mathrm{Al}$ coating is suppressed due to the uniform deformation of the superplastic Mg alloy.

It is also known that the load transfer delays the localized necking through the formation of multiple necking [46-48]. Therefore, the multiple necking can be an evidence of the occurrence of the load transfer. As mentioned in the previous section, the multiple necking was observed in the present study (see Fig. 4 (a)). Consequently, the Al-coated Mg alloy sheet in the present study underwent the load transfer, which can explain the large elongation of the pure $\mathrm{Al}$ as the coating material.

In order for this mechanism to arise, interfacial bonding between the $\mathrm{Al}$ and $\mathrm{Mg}$ alloy should be strong. Thus, the precise observation of the interface was conducted and the results are described below.

\subsection{Intermetallic compound layer}

An intermetallic compound layer of $\mathrm{Al}_{3} \mathrm{Mg}_{2}$ formed at the interface between the $\mathrm{Al}$ coating layer and the Mg alloy substrate during the hot extrusion [16]. Due to the hot forging process, the thickness of the intermetallic compound was reduced from 3.8 to $2.0 \mu \mathrm{m}$. The coating layer was broken, as indicated by arrows in Fig. 10 (a). The average thicknesses of the layer before and after the tensile test at $573 \mathrm{~K}$ and at $1.0 \times 10^{-3} \mathrm{~s}^{-1}$ were found to be approximately 2.0 and $10 \mu \mathrm{m}$, 
respectively. Interestingly, the broken intermetallic layer appeared to be repaired during the tensile test at $573 \mathrm{~K}$ at $1.0 \times 10^{-3} \mathrm{~s}^{-1}$, with excellent bonding observed at the interfaces of $\mathrm{Al} /$ intermetallic layer and intermetallic layer/Mg alloy substrate as can be seen in Fig. 10 (b). By observation, it can be suggested that the newly produced part of the intermetallic layer grew during the slow tensile deformation at the elevated temperature. Plastic deformation of this intermetallic compound layer was also observed in previous research [16]. Furthermore, the thickness of the intermetallic compound layer of $10 \mu \mathrm{m}$ after the maximum elongation may be negligibly small compared to the thickness of the sheet of $1.5 \mathrm{~mm}$. Therefore, it can be said that the intermetallic compound layer has no effect on the deformation behavior of both $\mathrm{Mg}$ alloy and $\mathrm{Al}$. However, in order to fully understand the effect of the intermetallic layer on the deformation behavior of the $\mathrm{Al}$-coated $\mathrm{Mg}$ alloy sheet, further investigation is still required.

\section{Conclusions}

The Al-coated Mg alloy sheet was successfully fabricated by hot forging. The sheet exhibited a large elongation of $550 \%$ in a tensile test at $573 \mathrm{~K}$ at a strain rate of $1.0 \times 10^{-3} \mathrm{~s}^{-1}$. Furthermore, the strain rate sensitivity exponent of the sheet was 0.4 , which indicates that the sheet possesses superplastic characteristics. Interestingly, despite such a large elongation, the Al layer still fully coats the $\mathrm{Mg}$ alloy substrate without breaking or debonding. It was illustrated that the elongation of $\mathrm{Al}$ is not very large when it is tensile-tested alone. Therefore, the mechanism of the large elongation of the $\mathrm{Al}$ on the $\mathrm{Mg}$ alloy substrate is considered to be suppression of necking by the uniform deformation of the Mg alloy substrate; that is, necking and subsequent local elongation of the Al coating layer are suppressed due to the uniform deformation of the superplastic Mg alloy substrate. The intermetallic layer formed at the interface between the $\mathrm{Al}$ coating layer and the $\mathrm{Mg}$ alloy substrate. The intermetallic layer was plastically deformed and grew during the superplastic elongation of the sheet.

\section{Acknowledgment}

This work was partially supported by "Nanotechnology Platform" Program of the Ministry of Education, Culture, Sports, Science and Technology (MEXT), Japan and by JSPS KAKENHI Grant Numbers $25 \cdot 1024$.

\section{References}

[1] Takaya M. J. Jpn. Inst. Light Met. 2000;50:567.

[2] Chino Y, Mabuchi M. J. Jpn. Inst. Light Met. 2001;51:498.

[3] Kohzu M. J. Jpn. Inst. Light Met. 2004;54:493.

[4] Gray JE, Luan B. J. Alloys Compd. 2002;336:88.

[5] Liu L, Xu R, Song G. Surf. Coat. Technol. 2010;205:332. 
[6] Li X, Liang W, Zhao X, Zhang Y, Fu X, Liu F. J. Alloys Compd. 2009;471: 408.

[7] Yang H, Guo X, Wu G, Ding W, Birbilis N. Corros. Sci. 2011;53:381.

[8] Hasumi A, Itoi Y, Sato E. J. Jpn. Inst. Light Met. 1980;30:432.

[9] Asada H, Iwasaki K. J. Jpn. Inst. Light Met. 1960;10:49.

[10] Pardo A, Casajús P, Mohedano M, Coy AE, Viejo F, Torres B, Matykina E. Appl. Surf. Sci. 2009;255:6968.

[11] Campo M, Carboneras M, Lopez MD, Torres B, Rodrigo P, Otero E, Rams Surf. Coat. Technol. 2009;203:3224.

[12] Pokhmurska H, Wielage B, Lampke T, Grund T, Student M, Chervinska N. Surf. Coat. Technol. 2008;202:4515.

[13] Parco M, Zhao L, Zwick J, Bobzin K, Lugscheider E. Surf. Coat. Technol. 2006;201:3269.

[14] Gao Y, Wang C, Pang H, Liu H, Yao M. Appl. Surf. Sci. 2007;253:4917.

[15] Wang AH, Xia HB, Wang WY, Bai ZK, Zhu XC, Xie CS. Mater. Lett. 2006;60:850.

[16] Tokunaga T, Matsuura K, Ohno M. Mater. Trans. 2012;53:1034.

[17] Mohan A, Yuan W, Mishra RS. Mater. Sci. Eng. A 2013;562:69.

[18] Chandra N. Inter. J. Non-Linear Mech. 2002;37:461.

[19] Kawasaki M, Langdon TG. J. Mater. Sci. 2007;42:1782.

[20] Kitazono K. J. Jpn. Inst. Light Met. 2013;63:160.

[21] Oikawa H. J. Jpn. Inst. Light Met. 1980;30:376.

[22] Humphries CW, Ridley N. J. Mater. Sci. 1974;9:1429.

[23] Livesey DW, Ridley N. Metall. Trans. A 1982;13:1619.

[24] Xinggang J, Jianzhong C, Longxiang M. J. Mater. Sci. Lett. 1993;12:1616.

[25] Miller DA, Langdon TG. Metall. Trans. A 1978;9:1688.

[26] Shei SA, Langdon TG. J. Mater. Sci. 1978;13:1084.

[27] Wei YH, Wang QD, Zhu YP, Zhou HT, Ding WJ, Chino Y. Mater. Sci. Eng. A 2003;360:107.

[28] Zelin MG. Acta Mater. 1997;45:3533.

[29] Lee S, Chinang C, Chu C, HSU C. Trans. Nonferrous Met. Soc. China 2010;20:576.

[30] Takayama Y, Tozawa T, Kato H. Acta Mater. 1999;47:1263.

[31] Cao WD, Lu XP, Conrad H. Acta Mater. 1996;44:697.

[32] Dirras G, Gubicza J, Tingaud D, Billard S. Mater. Chem. Phys. 2011;129:846.

[33] Chen CL, Tan MJ. Mater. Sci. Eng. 2001;298A:235.

[34] Blandin JJ, Hong B, Varloteaux A, Suery M, L’esperance G. Acta Mater. 1996;44:2317.

[35] Takayama Y, Tozawa T, Kato H. Acta Mater. 1999;47:1263.

[36] Abedi HR, Zarei-Hanzaki A, Khoddam S. Mater. Design 2011;32:2181.

[37] Mabuchi M, Iwasaki H, Higashi K. Acta Mater. 1998;46:5335. 
[38] Shaw WJD Mater. Lett. 1985;4:1.

[39] Lee SW, Chen YL, Wang HY, Yang CF, Yeh JW. Mater. Sci. Eng. 2007;464A:76.

[40] Yin DL, Zhang KF, Wang GF, Han WB. Mater. Lett. 2005;59:1714.

[41] Suzuki K, Ishida Y, Ichihara M. J. Jpn. Inst. Met. 1974;38:920.

[42] Jeong C, Oya T, Yanagimoto J. J. Mater. Process. Technol. 2013;213:614.

[43] Yanagimoto J, Oya T, Kawanishi S, Tiesler N, Koseki T. CIRP Annals. Manuf. Technol. 2010;59:287.

[44] Serror MH. J. Adv. Res. 2013;4:83.

[45] Schoene C, Scala E. Metall. Trans. 1970;1:3466.

[46] Hojo M, Iwasaki N, Sekino F, Ochiai S, Sakai S, Watanabe K. Cryogenics 1999;39:627.

[47] Ochiai S, Shimomura K, Murakami Y. Met. Sci. 1975;9:535.

[48] Liu HS, Zhang B, Zhang GP. Scr. Mater. 2011;64:13.

\section{Figure captions}

Fig. 1 (a) Schematic drawing of the equipment for hot forging with dimensions and (b) dimensions of the upper die and position of the thermocouple hole (all dimensions are in $\mathrm{mm}$ ).

Fig. 2 Cross sections of (a) hot-extruded Al-coated Mg alloy plate and (b) hot-forged Al-coated Mg alloy sheet.

Fig. 3 EBSD orientation maps obtained from: (a) Al coating layer part and (b) Mg alloy substrate part in the Al-coated Mg alloy sheet. Forging direction is vertical and the extrusion direction corresponds to ND axis. The black and white boundary lines represent high (more than $15^{\circ}$ ) and low $\left(2{ }^{\circ}\right.$ to $\left.15^{\circ}\right)$ angle grain boundaries.

Fig. 4 (a) The tensile specimens before and after the elongation of $550 \%$ at $573 \mathrm{~K}$ and at $1.0 \times 10^{-3}$ $\mathrm{s}^{-1}$. Stress-strain curves of the Al-coated Mg alloy sheet: (b) effects of tensile temperature at a strain rate of $1.0 \times 10^{-3} \mathrm{~s}^{-1}$ and (c) effects of strain rate at a tensile temperature of $573 \mathrm{~K}$.

Fig. 5 Effects of strain rate on the flow stress of the Al-coated Mg alloy sheet at different temperatures.

Fig. 6 (a) Longitudinal cross section of the specimen elongated to $550 \%$ at $573 \mathrm{~K}$ and at $1.0 \times 10^{-3}$ $\mathrm{s}^{-1}$ showing the superplastic elongation of the Al coating layer on the Mg alloy substrate. (b) Magnified image of the cross section of the specimen in the fractured part.

Fig. 7 Change of thickness of $\mathrm{Al}$ coating layer with respect to the distance from the fracture surface of the tensile test at $573 \mathrm{~K}$ and at $1.0 \times 10^{-3} \mathrm{~s}^{-1}$. The average thicknesses of Al coating layer of the samples after the extrusion [16] and hot forging are also shown in the figure.

Fig. 8 SEM fractographs of the tensile fracture surface of the specimen after the $550 \%$ of elongation: (a) low magnified image, (b) high magnified image of the Mg alloy part and (c) 
higher magnified image of the region indicated by square in (b).

Fig. 9 (a) The tensile specimens at $573 \mathrm{~K}$ and at $1.0 \times 10^{-3} \mathrm{~s}^{-1}$. Stress-strain curves of the Al-coated Mg alloy sheet: (b) pure $\mathrm{Al}$ and (c) Mg alloy (AZ80).

Fig. 10 Cross sections of the interface between $\mathrm{Al}$ coating layer and the Mg alloy substrate; (a) before tensile test and (b) after the tensile test at $573 \mathrm{~K}$ and at $1.0 \times 10^{-3} \mathrm{~s}^{-1}$. 
(a)

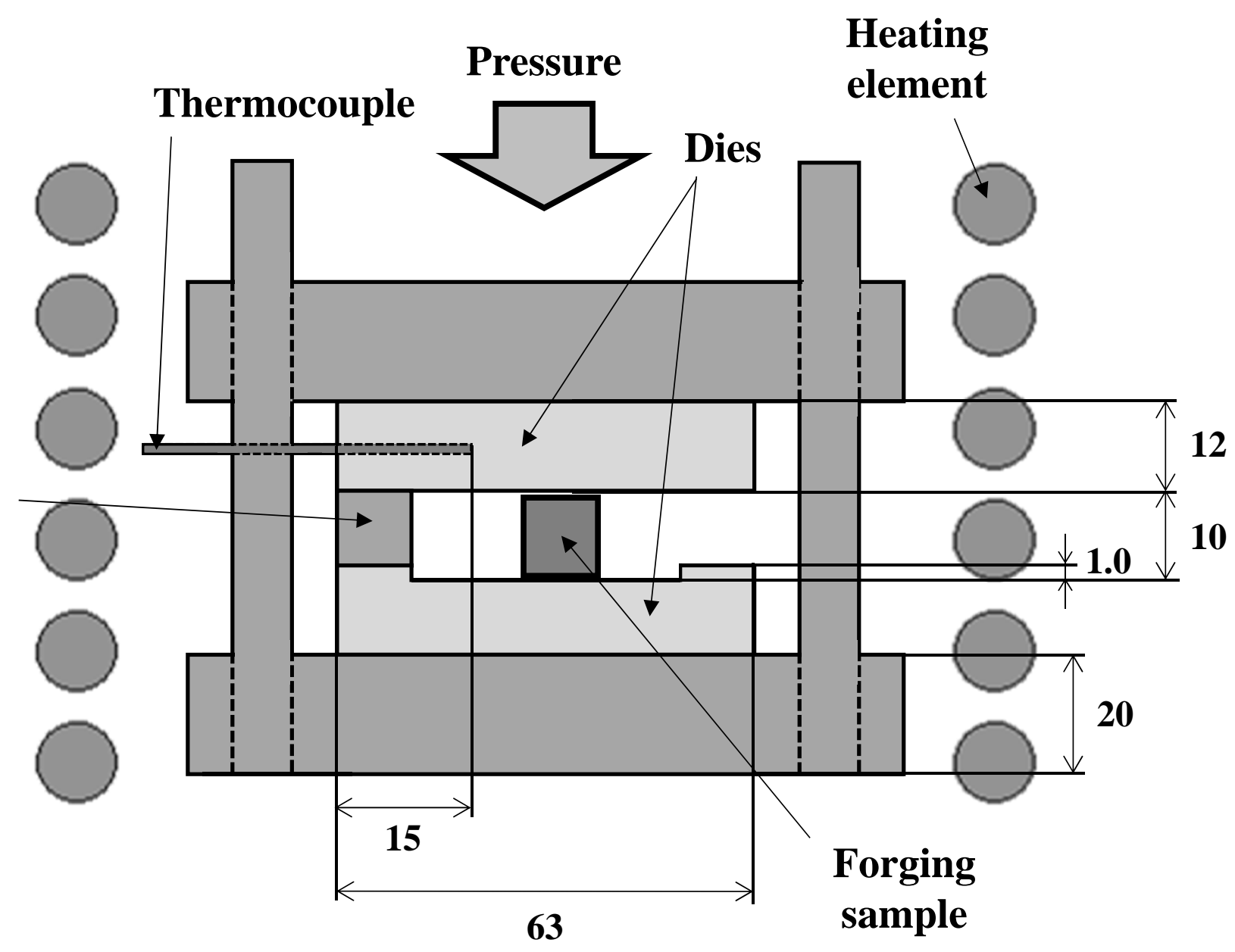

(b) Thermocouple hole

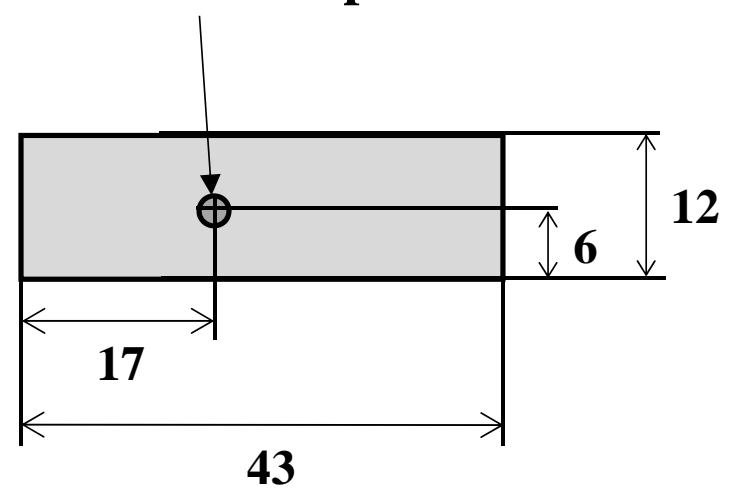


g. 2
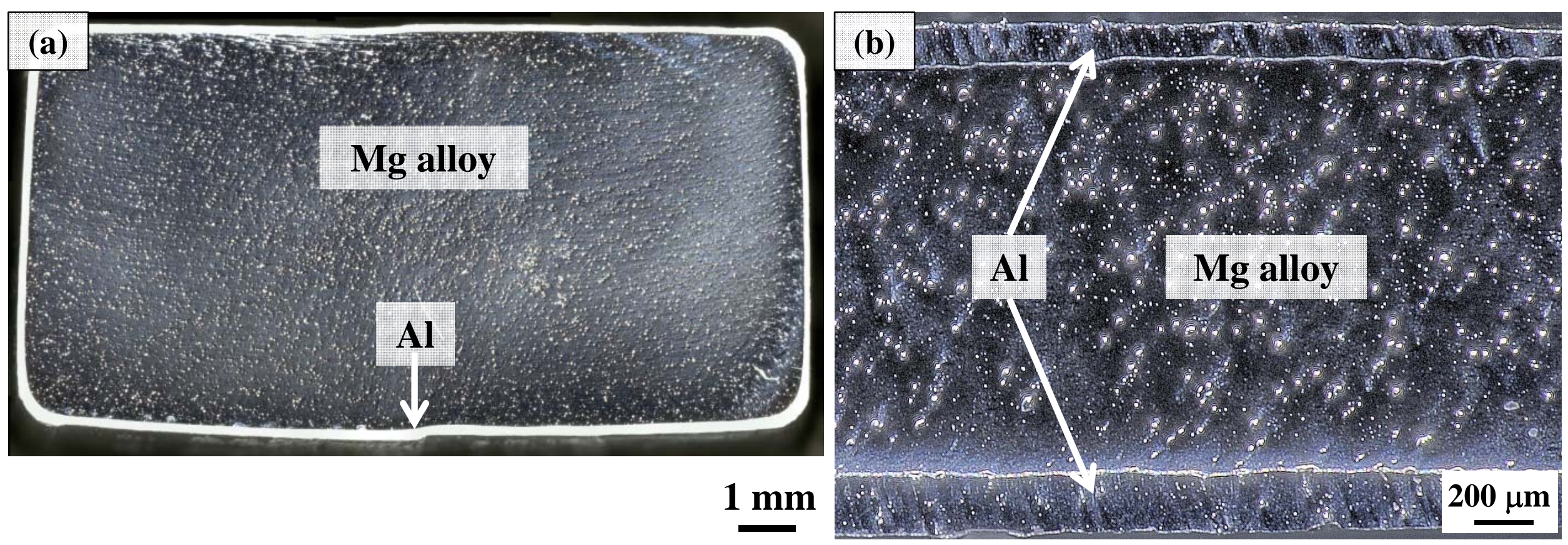
g. 3

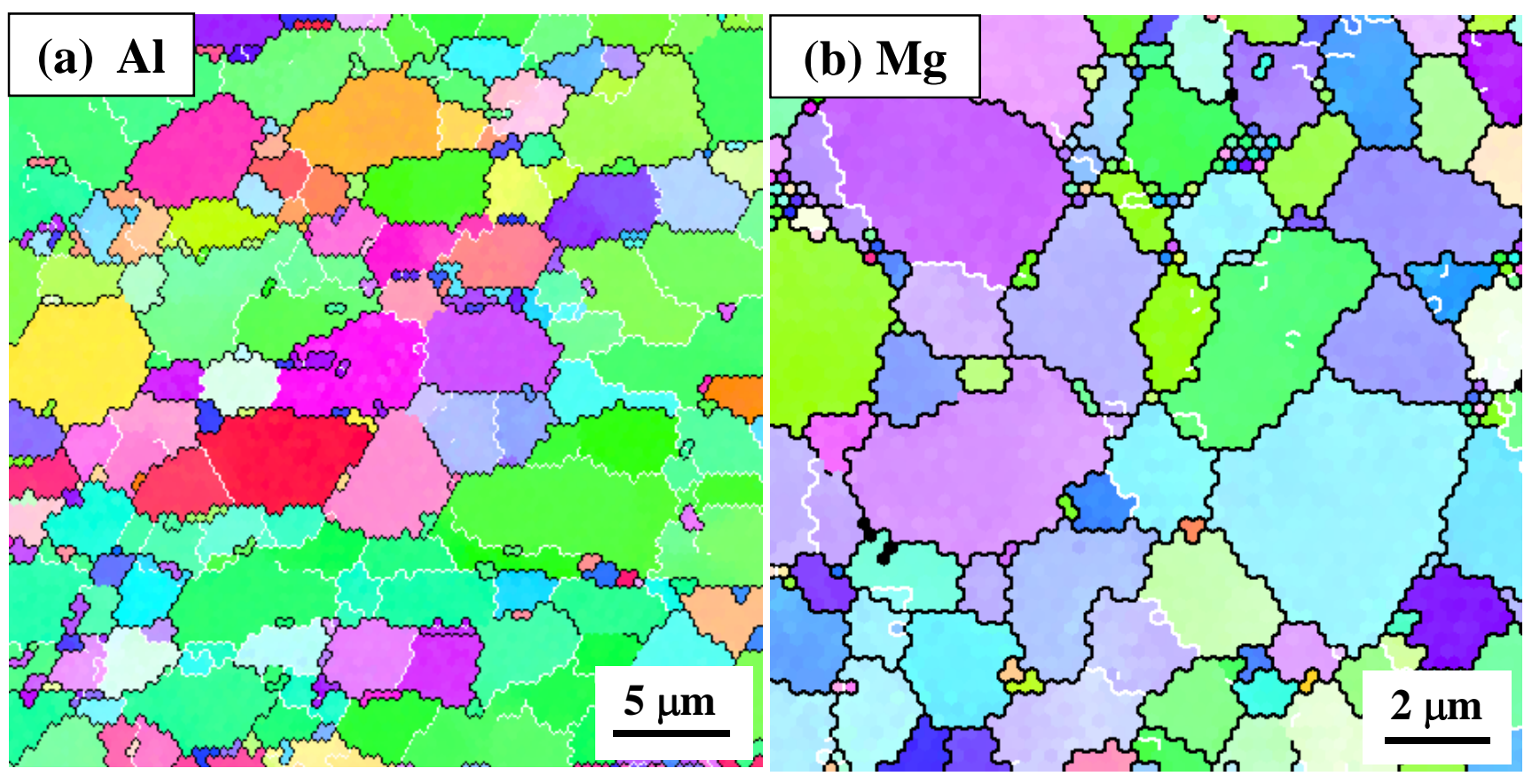

Aluminum

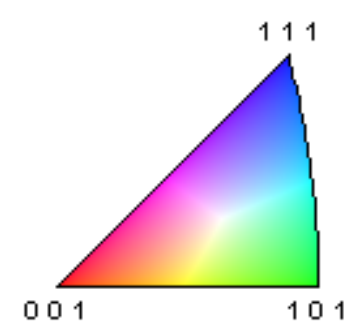

Magnesium

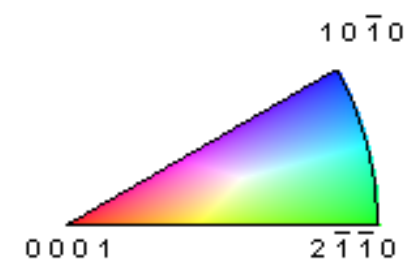


(a)

undeformed sample

deformed sample

$5 \mathrm{~mm}$

$573 \mathrm{~K}^{1.0 \times 10^{-3} \mathrm{~s}^{-1} \quad 550 \%}$

(b)

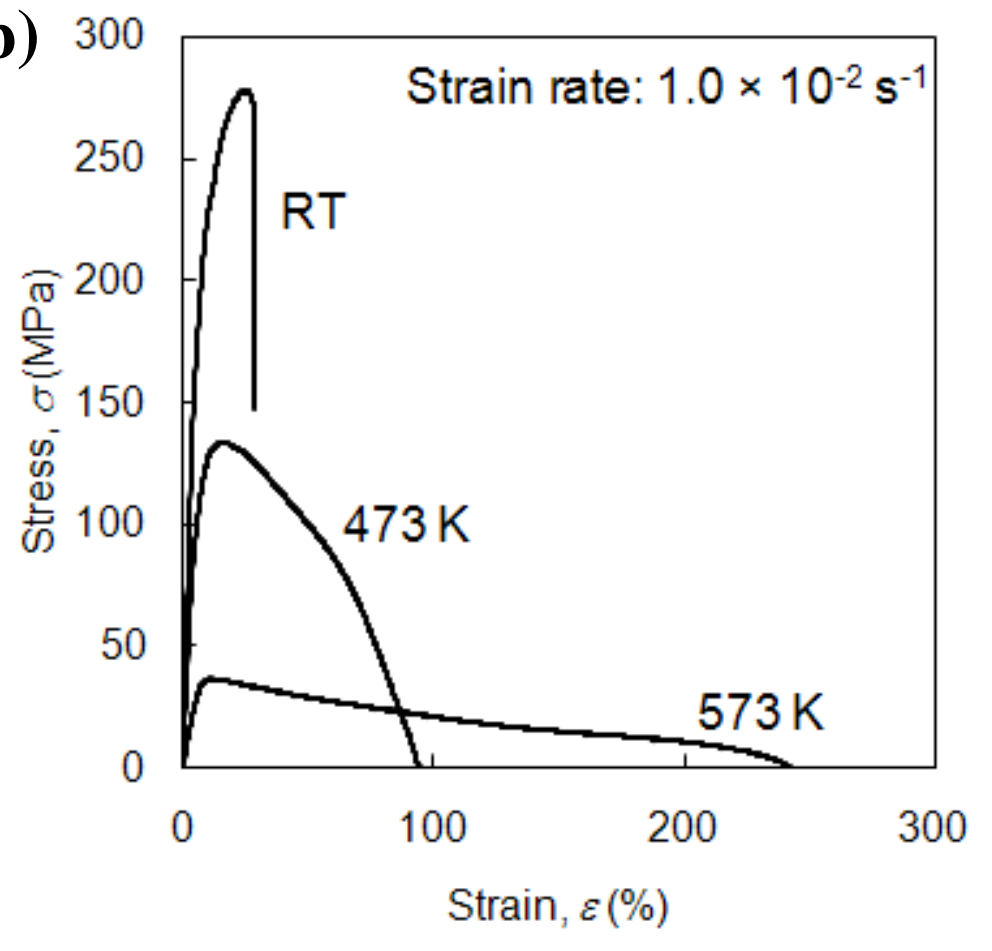

(c)

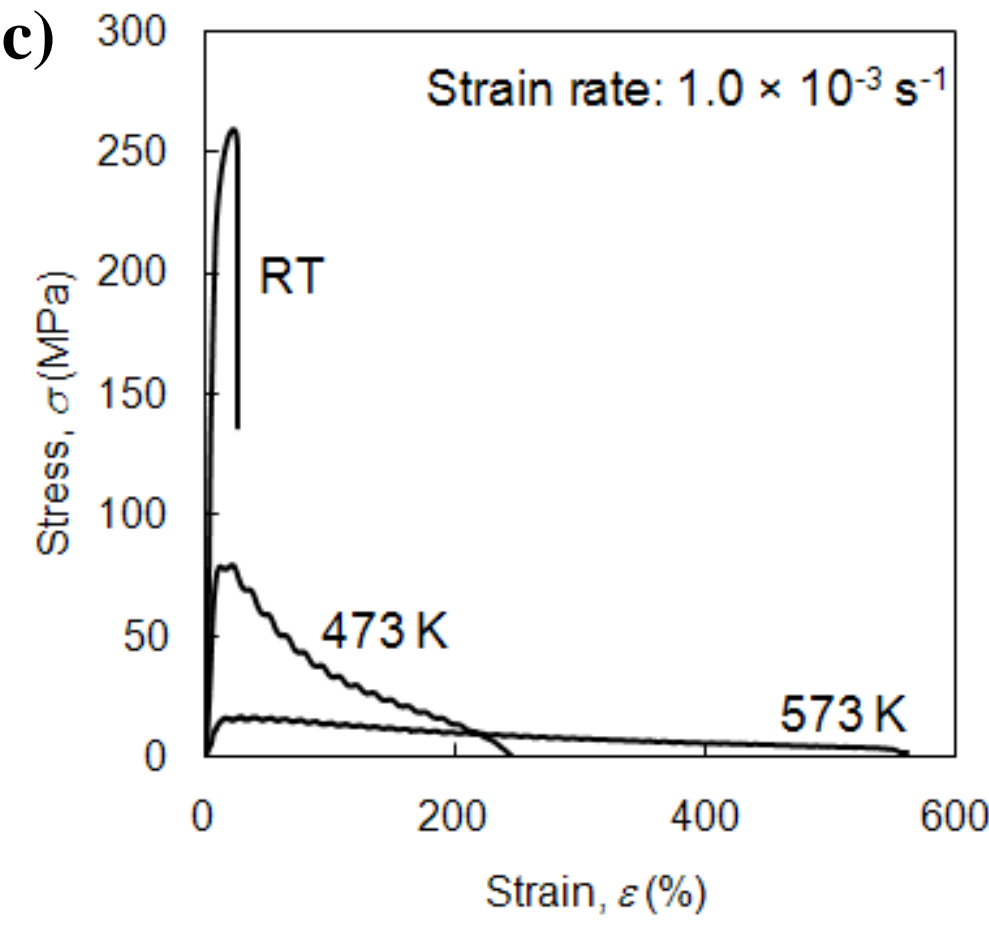


g. 5

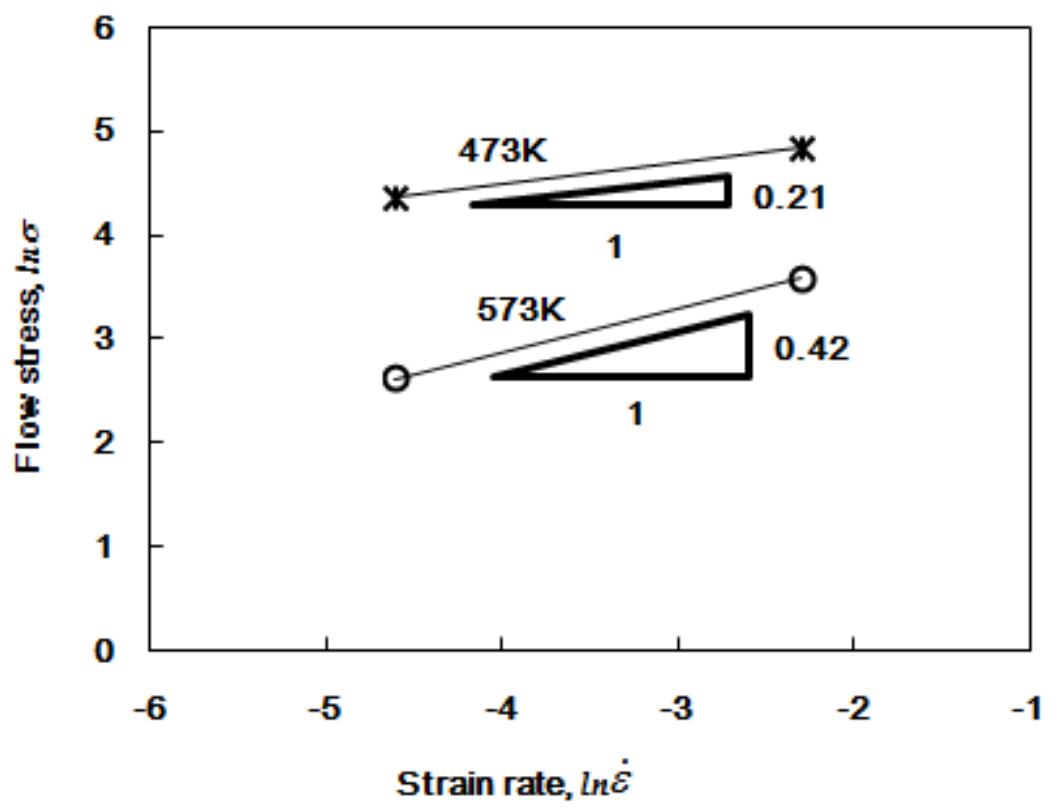


(a)

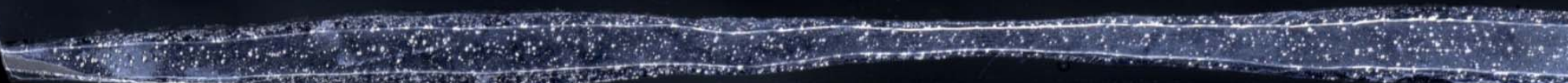

$\uparrow$

$1.0 \mathrm{~mm}$

Fracture surface

(b)

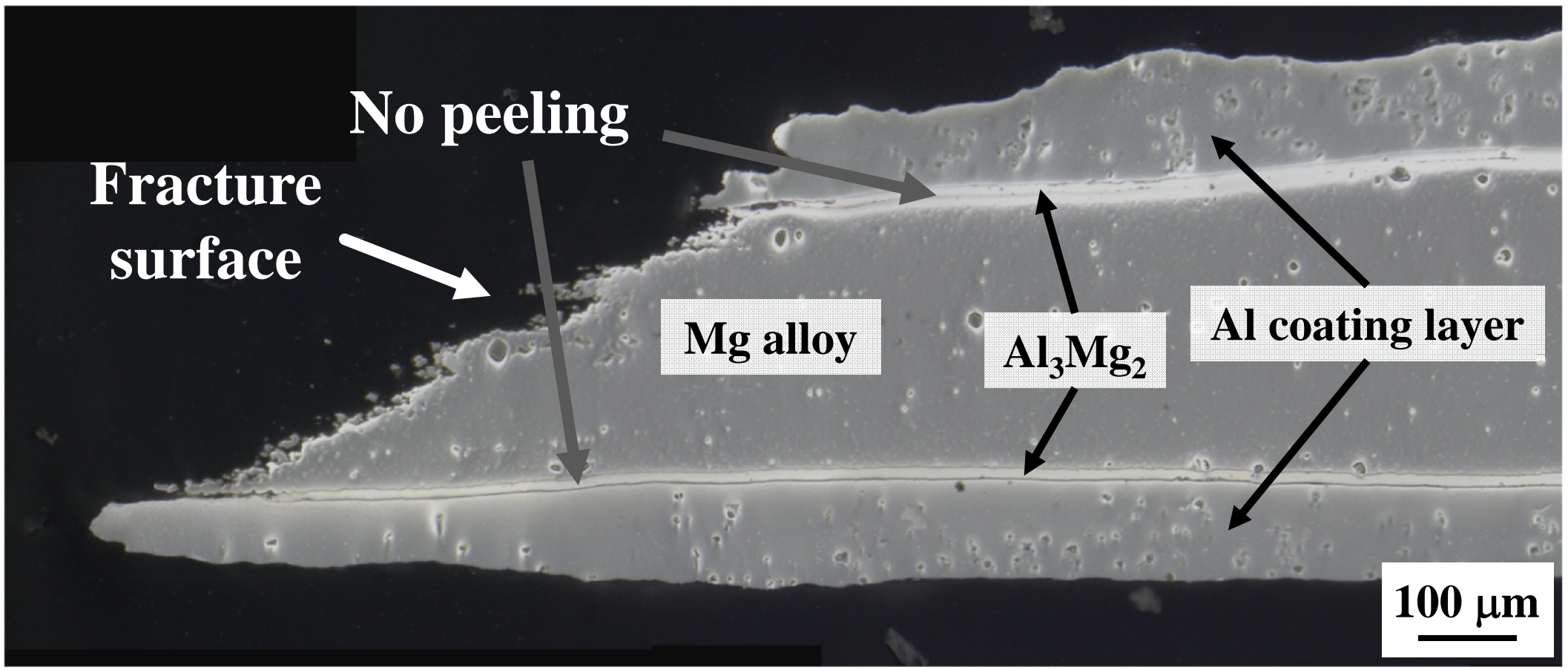


Fig. 7

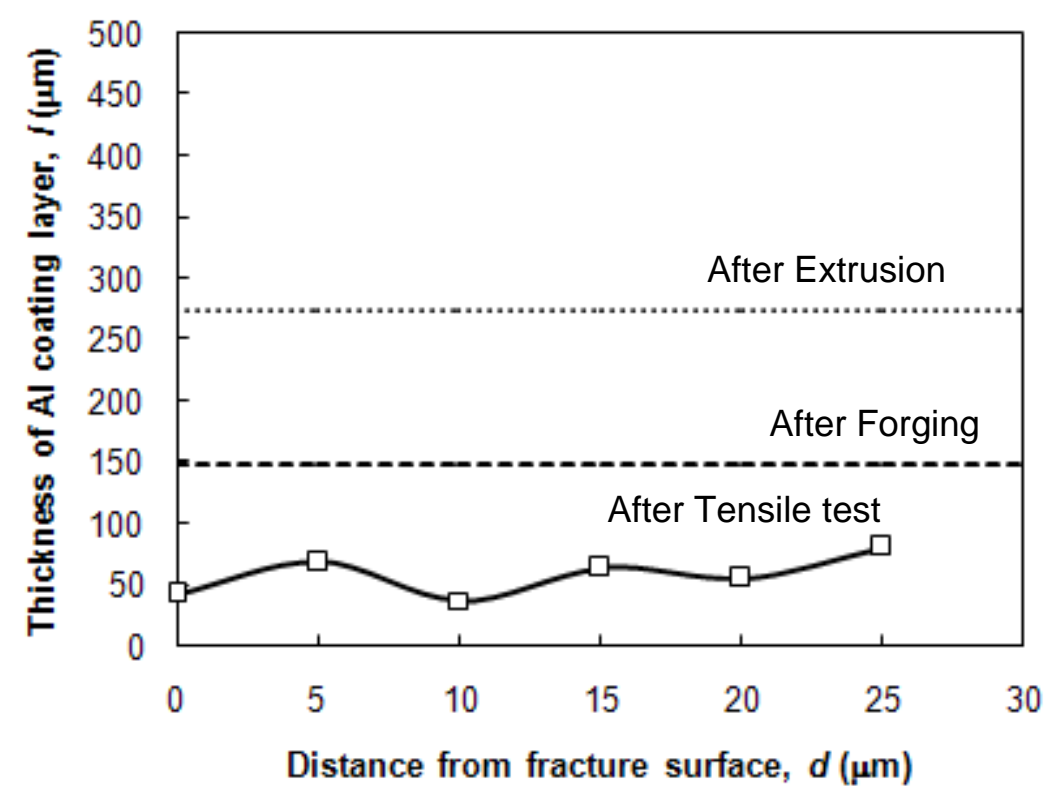


Fig. 8
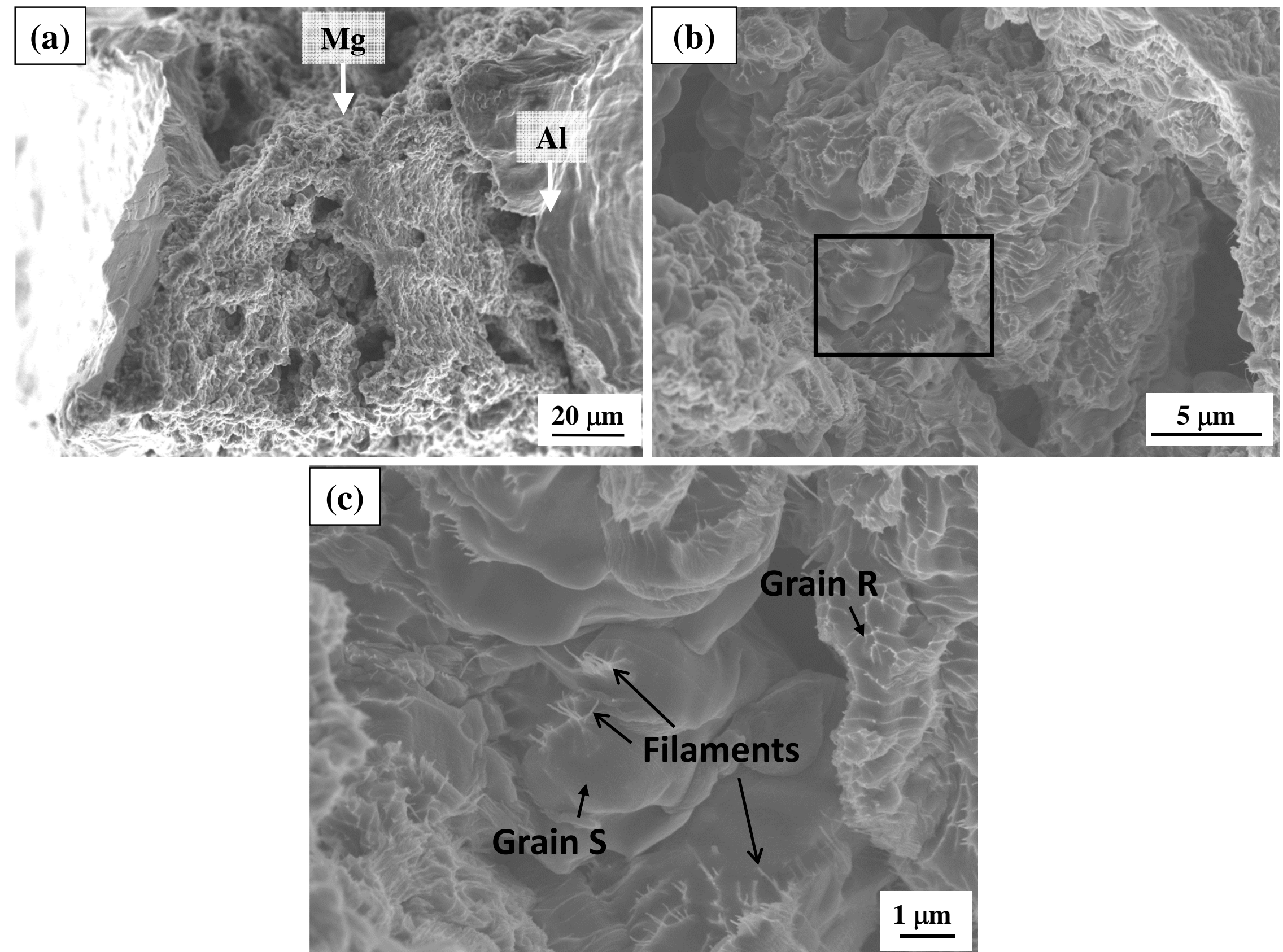
Fig. 9

(a)

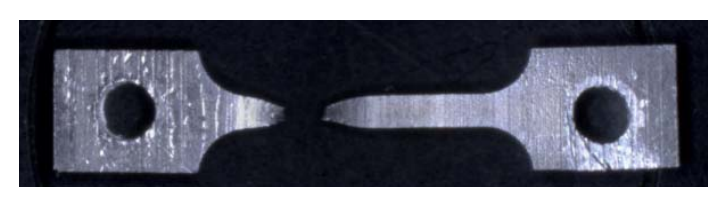

Pure Al

Mg alloy (AZ80)

$5 \mathrm{~mm}$

(b)

(c)
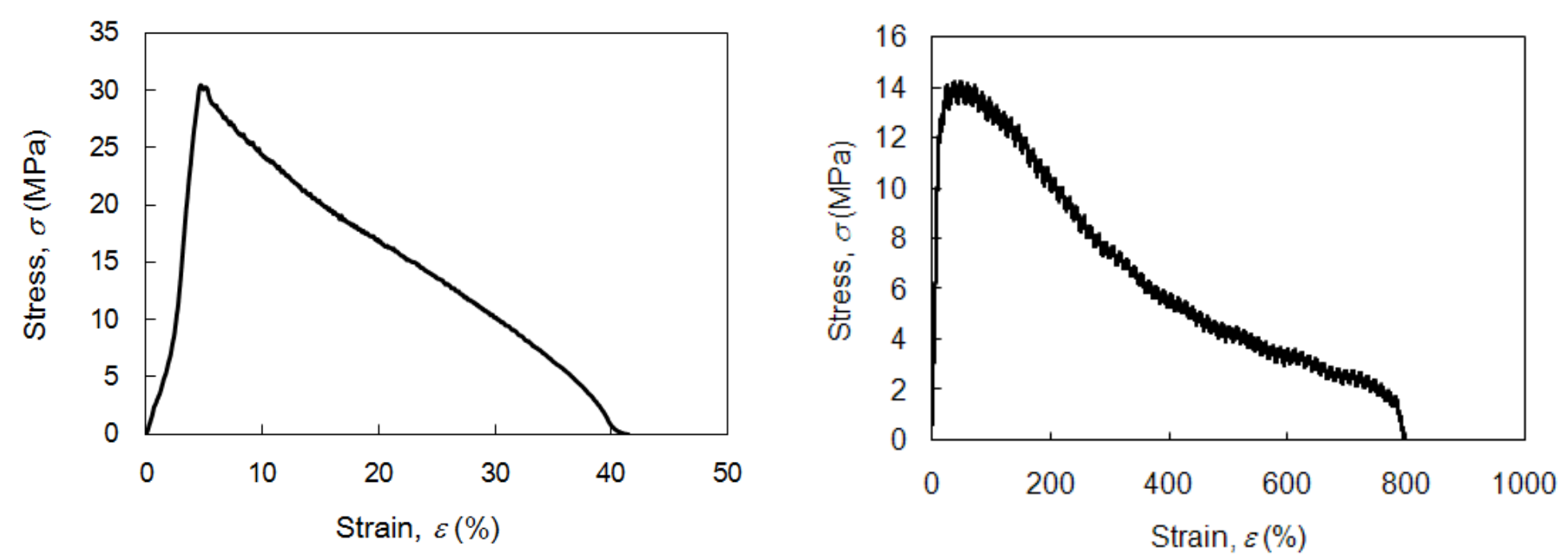
Fig. 10
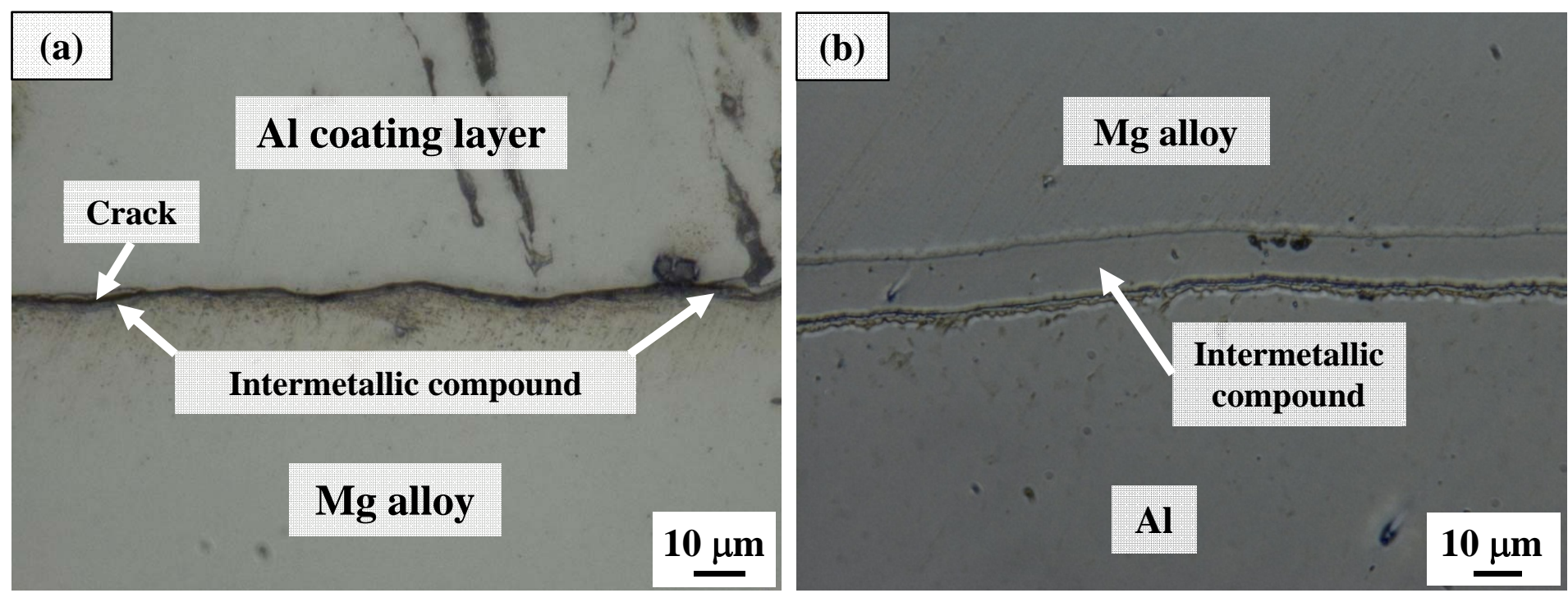